\title{
Welding simulation of tubular K-joints in steel S690QH
}

\author{
F. Zamiri \\ Chalmers University of Technology, Gothenburg, Sweden
}

J.-M. Drezet \& A. Nussbaumer

École Polytechnique Fédérale de Lausanne (EPFL), Lausanne, Switzerland

\begin{abstract}
Residual stress state in planar tubular K-joints, in the chord within the gap region between the two braces, is studied using numerical weld modelling. The motivation comes from past full-scale fatigue tests on tubular trusses made of various steel grades with sizes typical of bridge trusses, which shows that the cracking occurs at the hot spots located in this region. Residual stress field characterization is needed in order to assess its role in fatigue cracking, especially for the case of cracks occurring on the compression brace side. Comparison between residual stress field in a Y-joint and a $\mathrm{K}$-joint is made to assess the significance of restraining effect in the gap region. Phase transformations during welding and cooling down are determined and their impact on the final residual stress state is evaluated. Computed residual stresses are compared to the neutron diffraction measurements. Transient thermal field and cooling times substantially affect phase transformations. Therefore, their accurate reproduction in the analysis is important.
\end{abstract}

\section{INTRODUCTION}

Tensile welding residual stresses keep cracks open and thus lead to shorter fatigue lives even if welded components are subjected to, partially or fully, compressive external applied loads. Associated with welding residual stresses, distortions that result are also responsible for lower structural performance. Due to these detrimental effects on fatigue life of the structure, more realistic estimation of these stresses is necessary.

Conventional assumption for welding residual stresses is that they are of the order of yield strength of parent material. In general, through thickness residual stress distributions given by the codes, e.g. BS7910 (2005), are linear functions of yield strength. Residual stress measurements in tubular K-joints made of high-strength low-alloy (HSLA) steel by Zamiri (2014) have also shown peak residual stress values lower than yield stress. The objective of this paper is to explain the origin of these lower residual stresses using welding simulation of tubular K-joints for a steel S690.

Indeed, residual stresses can be estimated either by measurements or by numerical simulation of manufacturing process (rolling, machining, welding, etc.). Analytical prediction of residual stresses started by Rosenthal (1946) and Rykalin (1974). In early 1970s, Ueda applied finite element method for thermal stress analyses (Goldak and Akhlaghi 2005). Progresses in computational tools allowed for increasing the complexity of numerical models by implementing improved material laws, use of 3D models in lieu of 2D models, and incorporation of metallurgical transformations (Lindgren 2001).

The main source of welding residual stresses is hindered contraction of weld bead and heat affected zone by the surrounding parent material during cooling down stage. However, other important processes, namely metallurgical transformations, take place during the cooling down phase; these contribute significantly to the final state of residual stresses. The role of transformation strains has been emphasized by several authors, including Easterling (1992), NitschkePagel \& Wohlfhart (1992), and Voss et al. (1997).

Various concurrent processes happening during welding and subsequent cooling down, can be categorized into three major interacting fields: thermal domain, mechanical domain, and microstructure domain. Figure 1 schematically shows main interactions between thermal, mechanical and microstructural domains that occur during welding. Dark arrows show dominant effects while dotted arrows signify less important effects that generally are considered in the computations only implicitly. Temperature field affects both residual stress field and microstructural field, but the inverse effects are commonly considered as secondary. This assumption leads to de-coupling of the thermo-mechanical analysis into a staggered procedure. 


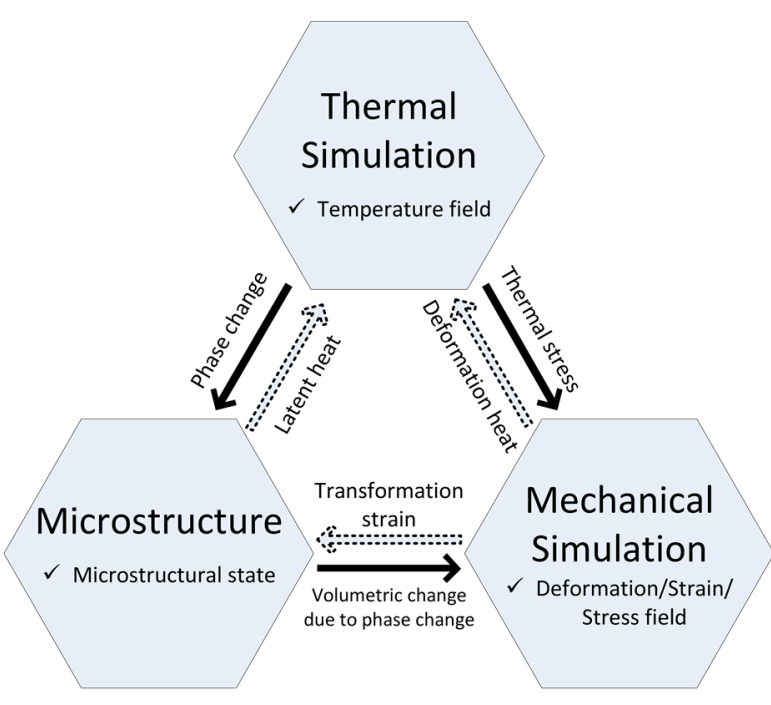

Figure 1. Interaction of temperature, mechanical, and microstructure fields during the welding and simplifications for welding simulation, after Radaj(2003). Bold arrows show the dominant effects and dotted arrows indicate factors that are not explicitly implemented in simulation.

\section{MODELLING OF WELDING}

The K-joint modeled here was part of a fatigue tested truss. Welding parameters and temperature history were registered at the time of fabrication of the truss for one of its $\mathrm{K}$-joints. Welding parameters are reported in Table 1. After the fatigue test finished, two of the K-joints were cut out of the truss and residual stress field at their gap region was evaluated using neutron diffraction method. The two K-joints were placed as attachments on the truss chords with no loading on their braces to prevent fatigue cracking in those joint. This was intentional so that as-welded residual stress would not change while the welding parameters, welding position, and welder's technic were similar to the rest of the K-joints in the truss. The welding temperature and residual stress measurements are compared to the results of finite element thermal and mechanical analyses in the following sections.

Table 1. Welding parameters for K-Joints.

\begin{tabular}{ll}
\hline Welding process & MAG 136 \\
Number of welding passes & 8 \\
Consumable & OK Tubrod 15.09 \\
Preheat temperature $\left[{ }^{\circ} \mathrm{C}\right]$ & 120 \\
Maximum interpass temperature $\left[{ }^{\circ} \mathrm{C}\right]$ & 250 \\
Arc power $[\mathrm{kW}]$ & $6.0-6.4$ \\
Average welding speed $[\mathrm{mm} / \mathrm{s}]$ & 7.4 \\
Gross heat input energy $[\mathrm{kJ} / \mathrm{mm}]$ & $0.81-0.86$ \\
Arc efficiency $[\%]^{\dagger}$ & 78 \\
\hline$\dagger$ Based on values given by Grong (1997).
\end{tabular}

$\dagger$ Based on values given by Grong (1997).

\subsection{Geometry and FE mesh}

The geometry is created with the method explained by Costa Borges (2008) and with dimensions mentioned in Table 2. Weld bead is divided into three parts (or passes) such that cross section area of weld pass number 1 is $20 \%$ of the total weld bead cross section, and cross section of weld passes 2 and 3 are $40 \%$ of the total cross section each. The length of the chord and braces in the joint are taken large enough to allow for reproducing the cooling times of the welded parts similar to the actual welding.

Table 2. Member sizes and non-dimensional geometric parameters of the studied K-joint.

\begin{tabular}{|c|c|c|c|}
\hline \multicolumn{2}{|c|}{ Nominal dimensions } & \multicolumn{2}{|c|}{ Non-dimensional parameter } \\
\hline Chord & $193.4 \times 20 \mathrm{~mm}$ & $\overline{\beta\left(\mathrm{d}_{1} / \mathrm{d}_{0}\right)}$ & 0.53 \\
\hline Brace & $101.6 \times 8 \mathrm{~mm}$ & $\gamma\left(\mathrm{d}_{0} / 2 \mathrm{t}_{0}\right)$ & 4.84 \\
\hline Eccentricity & $38 \mathrm{~mm}$ & $\mathrm{e} / \mathrm{d}_{0}$ & 0.20 \\
\hline$\theta$ & $60^{\circ}$ & $\tau\left(\mathrm{t}_{1} / \mathrm{t}_{0}\right)$ & 0.40 \\
\hline
\end{tabular}

*Nominal angle between the chord and the braces

Although the geometry has two symmetry planes, the heat loading is not symmetric Therefore, full symmetry conditions do not hold.

The geometry is discretized into 250,000 first order (linear) tetrahedral solid elements. The generated mesh for the K-joint is shown in Figure 2. Global element size is $16 \mathrm{~mm}$. This is reduced to $5 \mathrm{~mm}$ in the vicinity of weld bead region. For the region of interest (i.e. gap region), element size is refined even more, up to $2 \mathrm{~mm}$, to capture the residual stress profile with sufficient resolution. A convergence study is performed to investigate the sufficiency of mesh size. The effect of simulating only one brace (Y joint) is also investigated in this study.

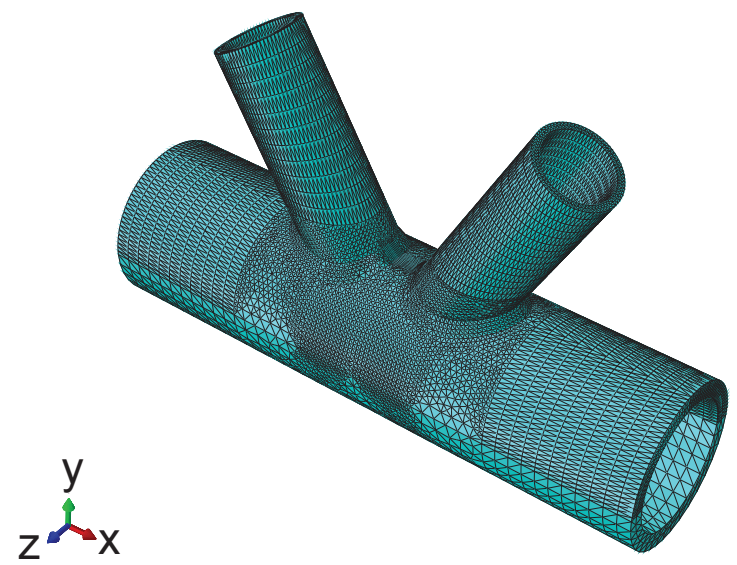

(a) Overall view of 3D mesh.

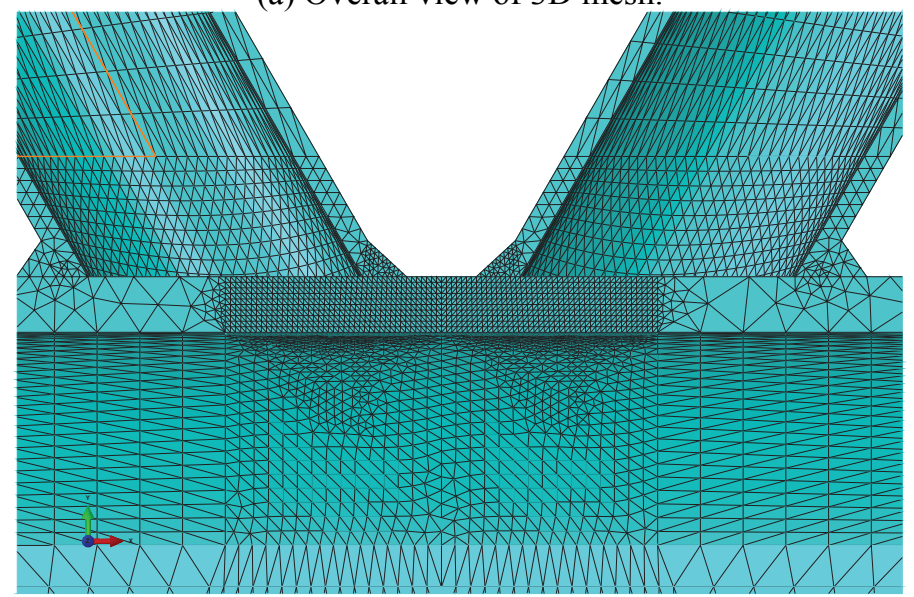

(b) Longitudinal section at the gap region.

Figure 2. Finite element mesh of the K-joint model. 


\subsection{Material properties}

Two approaches in modeling material behavior are available (Goldak \& Akhlaghi 2005). In the first approach, multi-phase steel material is considered as homogeneous and bulk material thermo-physical properties are given as the analysis input. Majority of the simulations in literature, e.g. Brickstad \& Josefson (1998), are carried out using this method. For this approach, there are techniques to take into account metallurgical effects in the analysis, for example by modifying coefficient of thermal expansion (Deng 2009). The second approach predicts the behavior of heterogeneous metallic material based on the contributions from its various microstructure constituents by using mixture rules. Generally linear mixture rules are used. With this approach, firstly the evolution of micro-structure during thermal cycle is evaluated. Knowing the phase fractions at each step of transient analysis, physical properties of the material is evaluated for that step. Generally, phase-based material properties approach is applied only for the mechanical analysis step, as is the case in this study.

When metallurgical effects are taken into account, the second modelling method, per-phase material properties, can yield more accurate results than first method, bulk material properties. The drawback of the phase-based approach is that considerably more material input data are required for the material model. Temperature-dependent mechanical properties for each phase and kinetics of phase transformation are required as input data. Both modeling approaches are utilized in this study. Bulk material properties are used in the models without phase transformation. For the model with phase transformation effects included, per-phase material data are used. Identical material properties are assumed for parent metal and weld metal. Barsoum (2008) and Dai and coworkers (2010) have reported acceptable simulation results using this assumption.

\subsubsection{Thermal properties}

Thermo-physical properties of steel S690QH were measured and reported by Mertens \& Lecomte-Beckers (2012) and are used in this study. Temperaturedependent specific heat capacity $\left(c_{p}\right)$ is shown in Figure 3. The values used here fit into the range of values given by Radaj (shaded area in Figure 3 ) and are in general agreement with the material input data used by other researches. Lindgren (2007) has emphasized the importance of latent heat of solidus-liquidus transformation (the peak at about $1500^{\circ} \mathrm{C}$ ) in the welding simulation, which is considered in the present study. Temperature-dependent thermal conductivity $\lambda$ in the range of $2.52 \times 10^{4}$ to $1.00 \times 10^{5}$ $\mu \mathrm{W} / \mathrm{mm} / \mathrm{K}$ (for liquid phase) is used. Detailed values are given in Zamiri (2014). For phase-based analysis, Morfeo uses the same thermal properties for all the constituents.

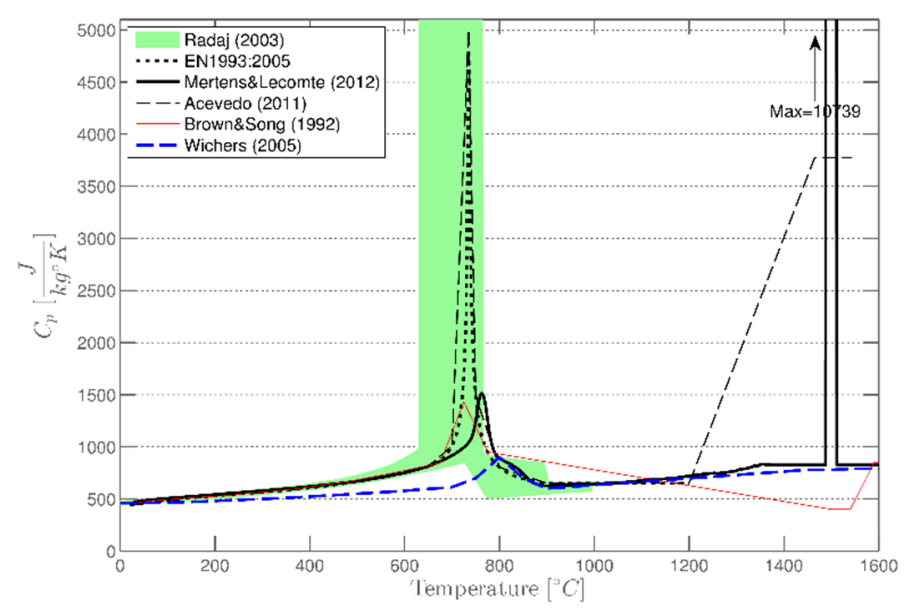

Figure 3. Specific heat capacity values from Richter (1973), EN1993 (2005), Acevedo et al. (2013), Brown \& Song (1992), Wichers (2006), and Mertens \& Lecomte-Beckers (2012)..

\subsubsection{Mechanical properties}

Temperature-dependent non-viscous mechanical properties are used. Hot tensile tests conducted on steel specimens and were in good agreement to recommended values of part 1-2 of Eurocode EN1993 (2005). Therefore, stress-strain curves given by Eurocode are used for the bulk material properties (Figure 4). For the phase-based model, yield stress of different constituents (bainitie, martensite, ferrite-pearlite, and austenite) are taken from literature as summarized in Zamiri (2014).

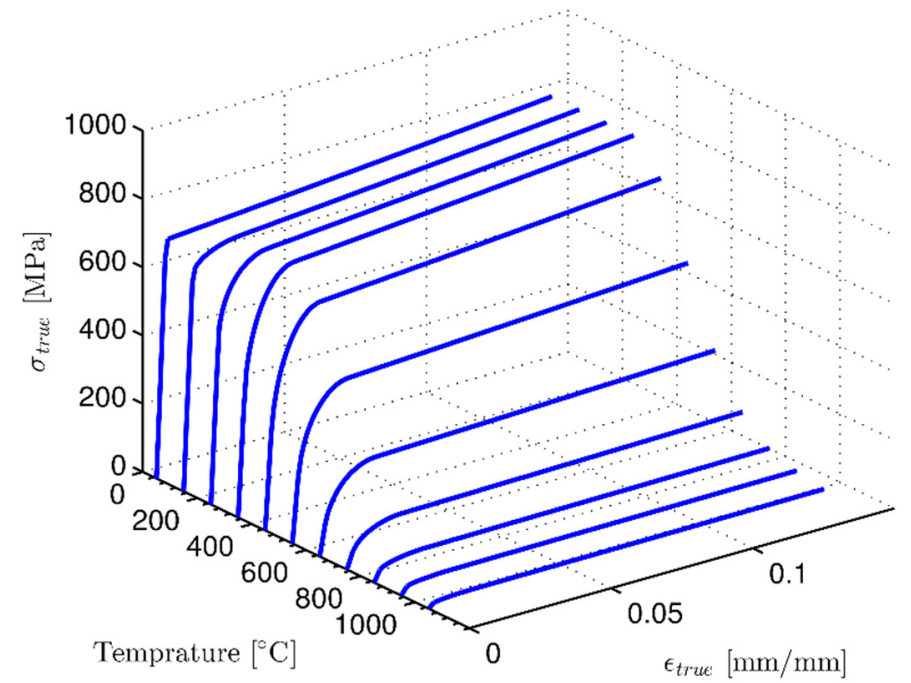

Figure 4.Eurocore 3 part 1-2 (2005) model for temperaturedependent stress-strain curve.

Coefficient of thermal expansion of steel material was measured by Mertens \& Lecomte-Beckers (2012). For phase-based model, coefficients of thermal expansion of various phases are measured from Gleeble dilatometry tests and experimental formulas for lattice parameters of constituents.

\subsubsection{Metallurgical properties}

Kinetics of phase change can be shown best by means of continuous cooling transformation (CCT) diagrams like the one shown in Figure 5 for S690QL. 
CCT diagram should be read by following individual cooling curves and reading their intersection with microstructure lines (thick lines in Figure 5) to estimate volume fraction of each constituent at the end of transformation. Cooling time from $800^{\circ} \mathrm{C}$ to $500^{\circ} \mathrm{C}$ $\left(\mathrm{t}_{8 / 5}\right)$, which is the temperature range that austenite decomposition occurs, is a commonly accepted index for representing thermal conditions in welding of low alloy steels (Grong 1997). Observing CCT diagrams, high cooling rates (or short cooling times) lead to a martensitic structure. This corresponds to welds with low heat input. On the other hand, a weld with a large heat input will cool down slowly and the final microstructure will be bainitic-ferritic.

For the phase-based modeling approach, phase fractions are calculated for each element based on the CCT data and transient temperature history at the end of thermal analysis step. Having the phase fractions and using a linear mixture rule, the program calculates mechanical properties of steel at the given location. These properties are then used in the mechanical analysis step. The effects of volume change due to martensitic transformation are taken into account by the change in the coefficient of thermal expansion. Initial composition of studied steel is considered as $84 \%$ bainitie and $16 \%$ martensite.

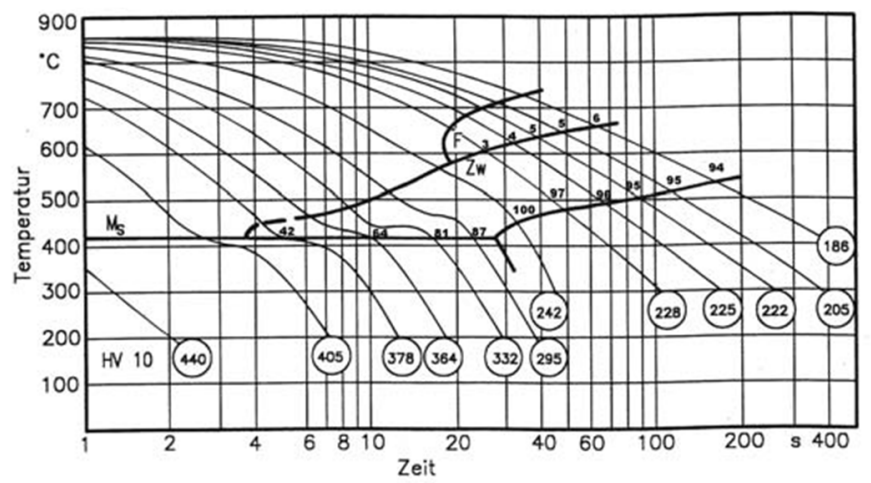

Figure 5. Continuous cooling transformation (CCT) curves for S690QL steel (Seyffarth et al. 1992).

\subsection{Heat source}

Input heat flux is calculated from the following equation:

$q=\eta U I q=\eta U I$

Where $\mathrm{q}=$ net heat flux $[\mathrm{J}], \eta=$ arc efficiency, $\mathrm{U}=$ arc electric tension [V], and $\mathrm{I}=\operatorname{arc}$ current $[\mathrm{A}]$. Arc efficiency accounts for heat losses by radiation and convection in the arc region and molten pool. With the values from Table 1, net heat flux is equal to $\mathrm{q}=4.8 \mathrm{~kW}$ and considering 8 weld passes, total heat power input is $\mathrm{Q}=38.4 \mathrm{~kW}$. Total net heat power deposited per unit length of weld is $\mathrm{Q} / \mathrm{v}=5.19 \mathrm{~kJ} / \mathrm{mm}$.

Due to the complex shape of multipass weld bead and individual weld passes, simplification of welding procedure is considered in the form of lumping the weld passes together as explained by Radaj (2003).
Total heat flux is divided into three parts, with the first equivalent weld pass (resembling root pass) having a share of $20 \%$ of total heat flux, while $40 \%$ of total heat flux is assigned to the $2^{\text {nd }}$ and $3^{\text {rd }}$ equivalent passes. Another distribution, assigning 33.3\% of total heat flux to each weld pass yields higher residual stresses and is used for some of the models (see Table 3 ). Figure 6 shows how the lumped weld passes compare to the actual welding passes.

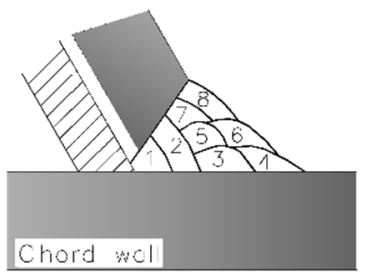

(a) (b)

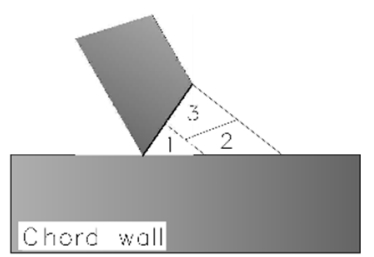

Figure 6. 8-pass weld (a) is reduced to three equivalent passes (b). Cross section of root pass is $20 \%$ of total weld cross section and two subsequent passes are $40 \%$ of total weld cross section each.

From Fourier law for heat conduction, it derives that cooling time $t_{8 / 5}$ for the case of moving heat source is a function of heat flux per unit length of weld (i.e. q/v ratio) (Radaj 2003). Since the power (q) of a lumped pass is greater than an individual weld pass, the torch speed (v) needs to be augmented proportionally in order to achieve a realistic estimation of cooling times in simulations. The augmented torch speed is applied to two of the models in this study.

Heat source shape is considered either as a cylindrical heat source with uniform heat intensity or Goldak's double ellipsoid model (Goldak \& Akhlaghi 2005). Both heat sources are calibrated such that they correctly reproduce the fusion zone and heat affected zone.

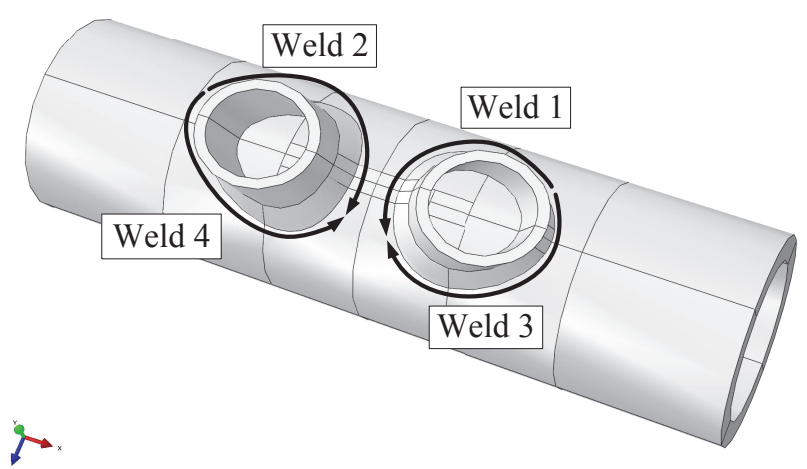

Figure 7. Sequence of welding passes. Welding start and stop points are shifted from crown toe and crown heel locations.

Weld torch trajectory for each weld pass is considered at the center of external face of that weld pass. The through-depth axis of the heat source is perpendicular to the weld face, which is in good agreement with Stockie's (1998) assumption of weld trajectory being coincident with bisector of the dihedral angle. 
Table 3. Summary of analyzed models and their parameters.

\begin{tabular}{llllll}
\hline Model & Torch speed & Material properties & Power distribution & Start/stop location & Heat source shape \\
\hline K-244-BLK-N-h2t & Normal & Bulk & $20 \%+40 \%+40 \%$ & heel-toe & Cylindrical \\
Y-244-BLK-N-h2t & Normal & Bulk & $20 \%+40 \%+40 \%$ & heel-toe & Cylindrical \\
Y-244-BLK-N-sh & Normal & Bulk & $20 \%+40 \%+40 \%$ & h-t shifted & Cylindrical \\
Y-333-BLK-A-sh & Augmented & Bulk & $30 \%+30 \%+30 \%$ & $\mathrm{~h}$-t shifted & Cylindrical \\
Y-333-NOL-VC-A-sh & Augmented & Phase-based & $30 \%+30 \%+30 \%$ & $\mathrm{~h}$-t shifted & Double ellipsoid \\
\hline
\end{tabular}

For the start/stop points, two variants are considered: (a) the heat source moves from crown toe towards crown heel, (b) the start points are shifted from crown locations to a location between saddle point and crown points as shown in Figure 7. The second variant is in coordination with the actual welding procedure, and is recommended by CIDECT (Zhao et al. 2000). The reason for choosing two variants is to assess the effect of start/stop points on residual stress distributions.

\subsection{Thermal initial and boundary conditions}

Initial temperature of whole welded piece is considered equal to the pre-heating temperature $\left(120^{\circ} \mathrm{C}\right)$. Ambient temperature is assumed as $20^{\circ} \mathrm{C}$. Morfeo takes into account heat flux due to convection while heat loss by radiation is not considered. Therefore, temperature-dependent film coefficient for convection heat flux is adjusted to account for the effect of heat loss by radiation as well.

\subsection{Analysis procedure}

Morfeo/Welding (2012) software is used for finite element analyses. It is a software package dedicated to manufacturing simulation tasks and can perform transient thermal-metallurgical-mechanical transient analyses.

Weld metal deposition is modeled by quiet element approach. All the elements in the weld bead region are available in the FE mesh from the beginning of analysis, but have near-zero material properties. Once the heat source reaches these elements, they are 'activated' by assigning real material properties to them. Element activation was used only for the mechanical analysis step.

Table 3 summarizes various models that are investigated here. Different parameters that are changed between models include shape of the joint (K- vs Yjoint), Torch speed (normal or augmented in analysis according to section 2.3), material properties, interpass power distribution, welding start/ stop location, and shape of the heat source shape.

\section{RESULTS}

\subsection{Thermal analysis results}

Estimated temperature time histories for two points located in fusion zone (FZ) and heat affected zone
(HAZ) at the crown toe are shown in Figure 8. Accurate estimation of cooling time $t_{8 / 5}$ is crucial for correct evaluation of microstructure transformations. The values calculated here as $t_{8} / 5=5$ to 5.5 seconds, are in good agreement with value of $t_{8 / 5}=3$ seconds, estimated from semi-analytical formulas given in Seyffarth et al. (1992). The calculated cooling times are short enough for formation of martensite to take place, according to CCT diagram of Figure 5.

The maximum registered temperature at measurement points located $5 \mathrm{~mm}$ from the weld toe at crown toe location was $350^{\circ} \mathrm{C}$ which is reproduced in all models with good accuracy.

Both FE models with normal and augmented torch speed give realistic sizes for the heat affected zone and fusion zone, when compared to weld macrograph. Figure 9 shows the estimated FZ and HAZ shapes for the three weld passes of model with augmented torch speed, compared to weld macrograph. The size of FZ is slightly underestimated by the model.

\subsection{Residual stress results}

Transversal component of residual stresses, i.e. residual stresses perpendicular to the weld line, are reported in this section. Transversal component is of more interest because of its impact fatigue cracking.

Figure 10 shows the comparison transverse residual stress field at the gap region for $\mathrm{K}$-joint and $\mathrm{Y}$ joint models. At close-to-surface locations (Depth $<3$ $\mathrm{mm}$ ), K-joint model considerably overestimates residual stresses compared to measurements. Study of residual stress build up at the end of each welding pass during simulation showed that the high input energy of the lumped passes on each brace affected a large part of the gap and when the effects from the weld lines of the two braces were superposed, the model would report high residual stress values. However, this was not the case for Y-joint model, since only one brace was modeled. Overall, Y-joint model with shifted start/stop locations worked better with the lumped pass weld model and gave more acceptable shape for residual stress profiles; albeit it underestimated transverse residual stresses in some locations. This model was selected as basis for subsequent analyses.

The effect of considering volumetric changes due to phase transformations on residual stress state is shown in Figure 11. As explained before, augmented speed models gave more accurate cooling times and were chosen for analysis of models with phase transformations. 


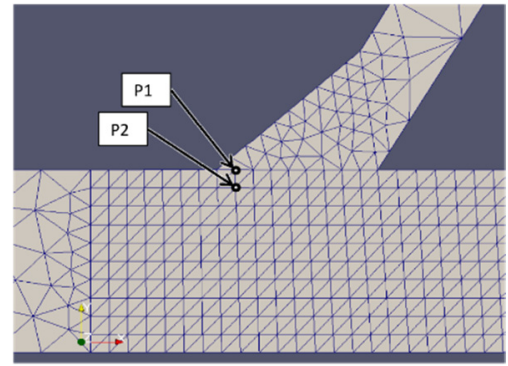

(a)

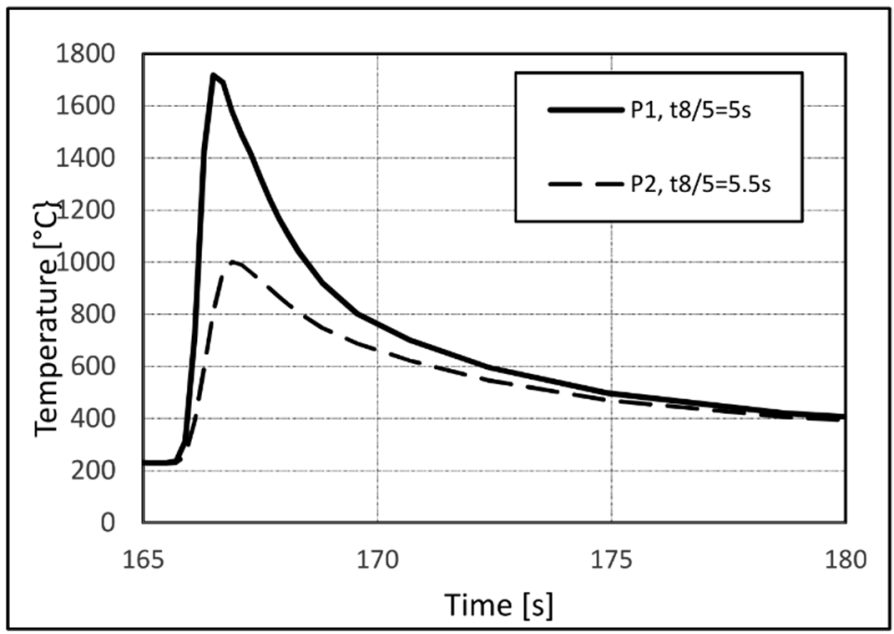

(b)

Figure 8. Temperature time history for points P1 and P2 (a) located in fusion zone and HAZ, respectively (crown toe). Only part of time history with the highest peak temperature is shown.

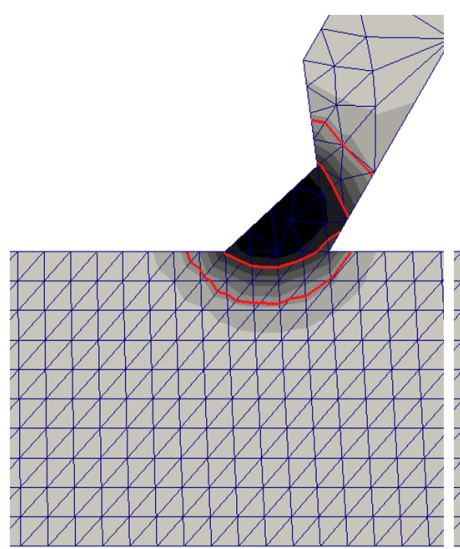

(a) Pass 1

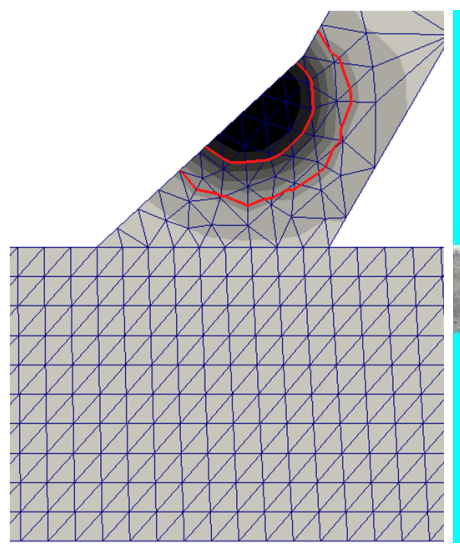

(c) Pass 3

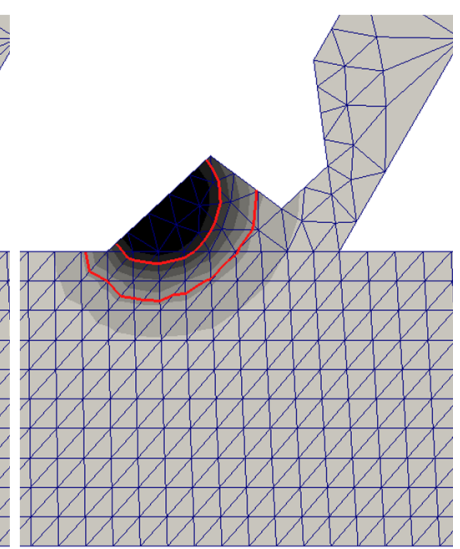

(b) Pass 2

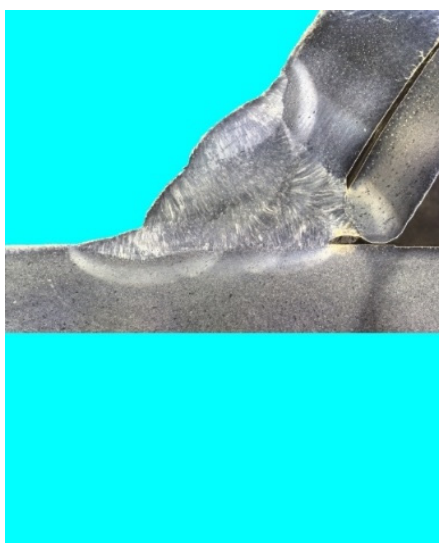

(d) Etched weld specimen
Figure 9.Estimated FZ and HAZ from model Y-333-NOL-VCA-sh (double ellipsoid heat source, augmented weld torch speed) compared to weld macrograph at crown toe location. Contour lines indicate $650^{\circ} \mathrm{C}$ and $1500^{\circ} \mathrm{C}$ ).

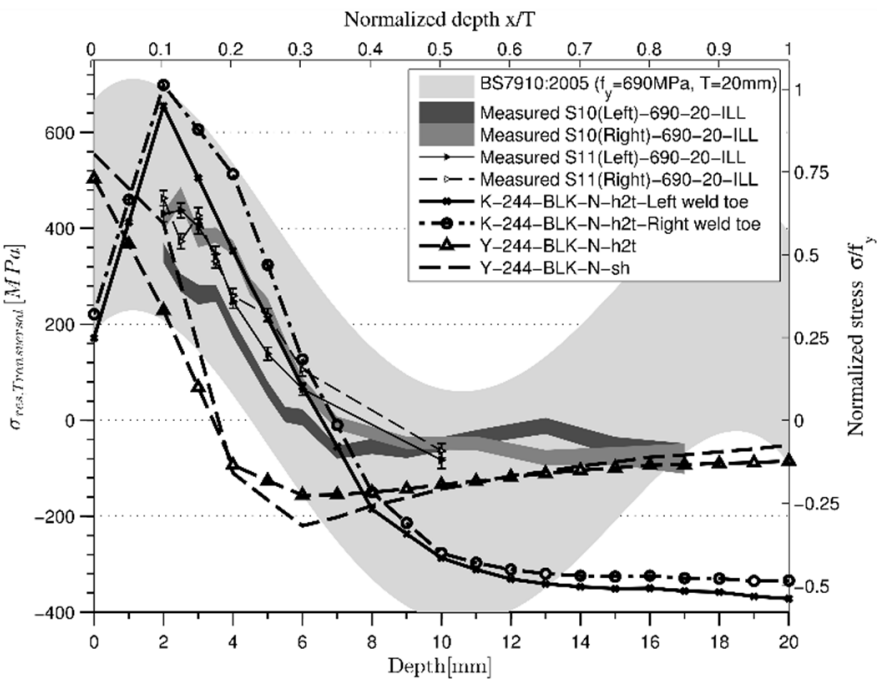

Figure 10. Comparison of computed transverse residual stress profiles for K-Joint and Y-joint, together with measurement data and value range suggested by BS 7910 (2005).

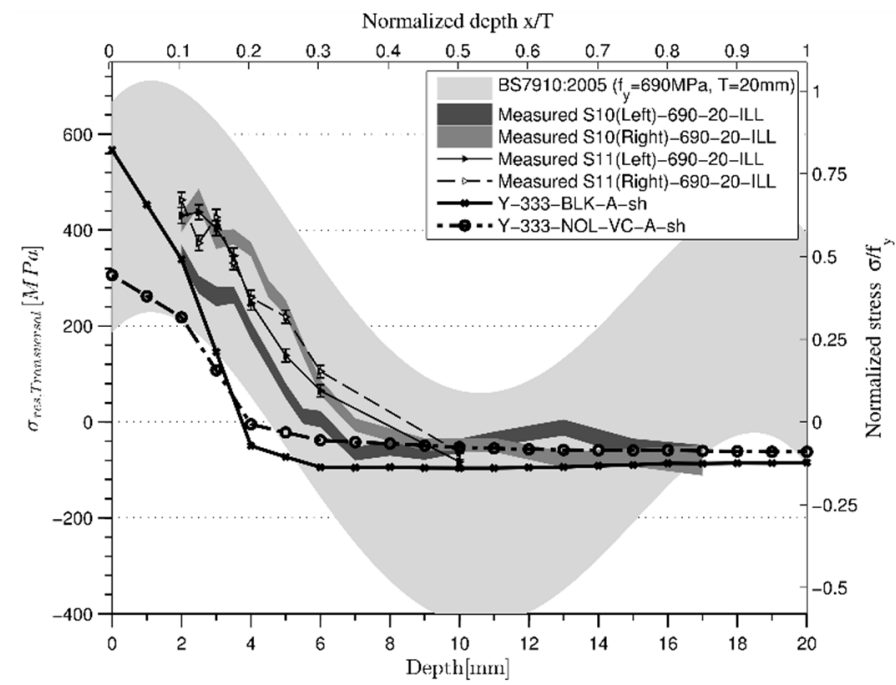

Figure 11. Comparison of effect of phase transformations on measured residual stress profiles. The wide band shows the range given by BS7910 (2005).

Calculated transversal peak residual stresses are below yield stress. Model with phase-based material data (Y-333-NOL-VC-A-sh) reports smaller peak residual stresses compared to the other model.

$\mathrm{Y}$-joint models slightly underestimate the location of minimum $\sigma_{\text {transversal }}$ profile at $0.3 \mathrm{~T}_{\text {ch }}\left(\mathrm{T}_{\mathrm{ch}}\right.$ being chord thickness) below weld toe, compared to $0.35 \mathrm{~T}_{\text {ch }}-0.4 \mathrm{~T}_{\text {ch }}$ from measurements. BS 7910 gives sinusoidal through-thickness residual stress profiles for transverse direction. It predicts that $\sigma$ transversal will increase at higher depths (measured from chord surface) once it reaches its minima at approximately mid-thickness. However, for the case of $\sigma_{\text {transversal, }}$ both calculated and measured residual stresses show only a small increase of stress with depth after the minimum is reached. 


\section{CONCLUSIONS}

Three-dimensional weld modeling of tubular K-joint is carried out in this study in order to evaluate residual stress field in the gap region of the K-joint. A staggered thermal-metallurgical-mechanical analysis scheme is used. Effect of volumetric changes due to martensitic transformation are taken into account. The computed residual stress profiles are compared to experimental measurements.

Comparing welding residual stress measurements in steel S690QH with a similar study on normal grade steel S355J2H by Acevedo(2012) shows that increase in residual stresses in HSLA is not proportional to the increase in yield strength of material. This is mainly associated with the solid state phase transformations that take place during the cooling down phase of these steels. Low heating power input in fine-grain HSLA steels causes rapid cooling, especially at the regions close to the surface. This leads to formation of martensite phase with a positive volume change that cancels part of thermal contraction strains.

Comparison of simulation results for residual stress field in the $\mathrm{K}$-joint and corresponding $\mathrm{Y}$-joint showed that $\mathrm{Y}$-joint model yields more acceptable residual stress values, when lumped pass heat source model is used.

Accurate reproduction of transient thermal field and cooling times is crucial when phase transformation effects are included in the model. For this reason, lumping of welding passes is a difficult decision. Since the last welding passes have more impact on the final residual stress field, it is advisable for subsequent simulations that the last two or three passes be modeled according to actual welding conditions (i.e. without lumping).

\section{ACKNOWLEDGMENTS}

This research was part of the project P816 "Optimal use of hollow sections and cast nodes in bridge structures made of S355 and S690 steel", supervised by the Versuchsanstalt für Stahl, Holz und Steine at the Technische Universität Karlsruhe, which was supported financially and with academic advice by the Forschungsvereinigung Stahlanwendung e. V. (FOSTA), Düsseldorf. The authors gratefully acknowledge their support. Thanks are also addressed to Zwahlen \& Mayr S.A. (Switzerland) who contributed to the project by fabrication of steel trusses. Neutron diffraction measurements were carried out at the Institut Laue-Langevin, Grenoble, France. Their contribution is sincerely acknowledged.

\section{REFERENCES}

Acevedo, C., Drezet, J.M., \& Nussbaumer, A., 2013. Numerical modelling and experimental investigation on welding residual stresses in large-scale tubular K-joints. Fatigue \& Fracture of Engineering Materials \& Structures, 36 (2), 177-185.

Acevedo, C., Evans, A., \& Nussbaumer, A., 2012. Neutron diffraction investigations on residual stresses contributing to the fatigue crack growth in ferritic steel tubular bridges. International Journal of Pressure Vessels and Piping, 95, 31-38.

Barsoum, Z., 2008. Residual stress analysis and fatigue assessment of welded steel structures. KTH, Stockholm, Sweden.

Brickstad, B. \& Josefson, B.L., 1998. A parametric study of residual stresses in multi-pass butt-welded stainless steel pipes. International Journal of Pressure Vessels and Piping, 75 (1), 11-25.

Brown, S. \& Song, H., 1992. Finite element simulation of welding of large structures. Journal of engineering for industry, 114 (4), 441-451.

BS 7910, 2005. Guide to methods for assessing the acceptability of flaws in metallic structures. British Standards Institution.

Costa Borges, L.A., 2008. Size effects in the fatigue behaviour of tubular bridge joints (Thesis No. 4142). EPFL, Lausanne.

Dai, H., Francis, J.A., \& Withers, P.J., 2010. Prediction of residual stress distributions for single weld beads deposited on to SA508 steel including phase transformation effects. Materials Science and Technology, 26 (8), 940949.

Deng, D., 2009. FEM prediction of welding residual stress and distortion in carbon steel considering phase transformation effects. Materials \& Design, 30 (2), 359-366.

Easterling, K.E., 1992. Introduction to the physical metallurgy of welding. 2nd ed. Oxford; Boston: Butterworth Heinemann.

EN1993, 2005. Eurocode 3: Design of steel structures - Part 12:General rules - Structural fire design. Brussels: European Committee for Standardization.

Goldak, J.A. \& Akhlaghi, M., 2005. Computational welding mechanics. Springer Verlag.

Grong, Ø., 1997. Metallurgical Modelling of Welding (2nd Edition). Maney Publishing.

Lindgren, L.-E., 2001. Finite element modeling and simulation of welding part 1: Increased complexity. Journal of Thermal Stresses, 24 (2), 141-192.

Lindgren, L.E., 2007. Computational Welding Mechanics: Thermomechanical and Microstructural Simulations. CRC Press.

Mertens, A. \& Lecomte-Beckers, J., 2012. Rapport d'essais: Caractérisation thermophysique de 2 chantillons d'acier. Liège, Belgium: Université de Liège-Department A\&M-Science of Metallic Materials (MMS).

MORFEO, 2012. v1.7.5 User's Manual. Gosselies, Belgium: Cenaero.

Nitschke-Pagel, T. \& Wohlfahrt, H., 1992. Residual stress distributions after welding as a consequence of the combined effect of physical, metallurgical and mechanical sources. In: Mechanical Effects of Welding. Springer, $123-134$

Radaj, D., 2003. Welding residual stresses and distortion: Calculation and measurement. DVS-Verlag. 
Richter, F., 1973. Die wichtigsten physikalischen Eigenschaften von 52 Eisenwerkstoffen. Stahleisen-Sonderberichte, Duesseldorf: Verlag Stahleisen, 8.

Rosenthal, D., 1946. The theory of moving sources of heat and its application to metal treatments. In: Transactions of ASME. 849.

Rykalin, N.N., 1974. Energy Sources Used for Welding. Soudage et Techniques Connexes l (12), 471-485.

Seyffarth, P., Meyer, B., \& Scharff, A., 1992. Großer Atlas Schweiß-ZTU-Schaubilder. Deutscher Verlag für Schweißtechnik DVS-Verlag GmbH.

Stockie, J.M., 1998. The geometry of intersecting tubes applied to controlling a robotic welding torch. Mapel Tech, 19 (2), 2.

Voss, O., Decker, I., \& Wohlfahrt, W., 1997. Consideration of microstructural transformations in the calculation of residual stresses and distortion of larger weldments. In: H. Cerjak, ed. Mathematical modelling of weld phenomena 4. Presented at the Numerical Analysis of Weldability 4, 584-596.

Wichers, M., 2006. Schweißen unter einachsiger, zyklischer Beanspruchung Experimentelle und numerische Untersuchungen(Welding under uniaxial cyclic loads - Experimental and numerical research). Universitätsbibliothek Braunschweig.

Zamiri, F., 2014. Welding Simulation and Fatigue assessment of Tubular K-joints in High Strength Steel. École Polytechnique Fédérale de Lausanne, Lausanne, Switzerland.

Zhao, X.L., Herion, S., Packer, J.A., Puthli, R.S., Sedlacek, G., Wardenier, J., Weynard, K., Van Wingerde, A.M., \& Yeomans, N.F., 2000. Design guide for circular and rectangular hollow section joints under fatigue loading. CIDECT, Comité International pour le Développement et l'Etude de la Construction Tubulaire. Köln, Germany: TÜV-Verlag. 